\title{
Alar Rim Deformities in Korean Primary Rhinoplasty Patients
}

\author{
Su Jin Kim, MD, PhD ${ }^{1}$, Ho Yun Lee, MD, $\mathrm{PhD}^{2}$, Tae Hyun Kim, $\mathrm{MD}^{3}$, \\ Tae Hoon Kim, MD ${ }^{3}$, and Kun Hee Lee, MD, $\mathrm{PhD}^{3}$ \\ ${ }^{1}$ Department of Otorhinolaryngology-Head and Neck Surgery, National Medical Center, Seoul, Republic of Korea \\ ${ }^{2}$ Department of Otorhinolaryngology-Head and Neck Surgery, Ewha Womans University College of Medicine, Seoul, Republic of Korea \\ ${ }^{3}$ Department of Otorhinolaryngology-Head and Neck Surgery, School of Medicine, Kyung Hee University, Seoul, Republic of Korea
}

Background and Objectives: The alar-columellar relationship plays an important role in the esthetic balance of the nose. We analyzed alar rim deformities and aesthetic concerns and expectations among patients by deformity type in Korean primary rhinoplasty patients.

Materials and Methods: Retrospective photographic analysis was done on 336 patients planning to undergo primary rhinoplasty at Kyung Hee University Hospital at Gangdong. We categorized their alar rim deformities as normal, hanging columella, retracted columella, hanging ala, retracted ala, convex ala, concave ala, thick ala, and a combination of the above. Patients' aesthetic concerns and expectations about their nose were analyzed by preoperative questionnaire.

Results: Of the enrolled patients, 38 (11.3\%) had no alar rim deformities, and the other 298 patients (88.7\%) had one or more deformities. The most prevalent alar rim deformity was hanging ala (59.2\%), followed by convex ala (53.3\%) and thick ala (32.1\%). Male patients were more likely to have convex ala and retracted columella than female patients. More than one-half of the patients (64.1\%) had two or more deformities and tended to be young $(\mathrm{p}=0.028)$. Patients with thick ala had several reasons for being dissatisfied with their nose and various demands for correction.

Conclusion: Distinctive characteristics of alar rim deformities should be considered in surgical planning in order to obtain satisfactory results in Korean primary rhinoplasty patients.

Keywords: Rhinoplasty; Deformities; Photography.

\section{INTRODUCTION}

The alar-columellar relationship plays an important role in the esthetic balance of the nose. Alar rim deformities, defined by the alar-columellar relationship, are one of the most common problems that rhinoplasty patients face preoperatively or postoperatively. ${ }^{1)}$ Thus, detailed assessment and classification of the deformities are essential to achieve a successful surgical correction. $^{2)}$

The ideal alar rim is defined by a smooth contour with a slight arch, with the highest point of the alar rim located midway between the tip-defining points and the columellar-lobular angle. ${ }^{13)}$ Additionally, the distance from the long axis of

Received: May 26, 2021 Revised: August 2, 2021

Accepted: September 3, 2021

Address for correspondence: Kun Hee Lee, MD, PhD, Department of Otorhinolaryngology-Head and Neck Surgery, Kyung Hee University Hospital at Gangdong, 892 Dongnam-ro, Gangdong-gu, Seoul 05278, Republic of Korea Tel: +82-2-440-6181, Fax: +82-2-440-7325, E-mail: nose4u@gmail.com

This is an Open Access article distributed under the terms of the Creative Commons Attribution Non-Commercial License (https://creativecommons.org/licenses/by$\mathrm{nc} / 4.0$ ) which permits unrestricted non-commercial use, distribution, and reproduction in any medium, provided the original work is properly cited. the nostril to either the alar rim or the columella should be within 1 to $2 \mathrm{~mm}^{3{ }^{34)}}$ From the basal view, the two alar rims should fall in a straight line on a side of an equilateral triangle. ${ }^{5)}$ By Gunter's classification, ${ }^{3)}$ alar rim deformities can be classified into six types from the lateral view: hanging columella (HC), retracted ala (RA), a combination of $\mathrm{HC}$ and RA, hanging ala (HA), retracted columella (RC), and a combination of HA and RC. In addition to Gunter's classification, alar rim deformities can be divided into three types from the basal view: concave ala (CA), convex ala (VA) caused by convex lateral crus, and CA caused by thick ala (TA). ${ }^{5}$

Innate or acquired alar deformities disturb the balance of the nose and result in an unpleasant appearance, and they are frequently observed among patients seeking rhinoplasty. Racial differences should also be taken into account before defining the types of alar rim deformity. For example, RA is one of the most common alar deformities in Caucasians, ${ }^{2)}$ whereas it is a rare condition in Asians but is often found as a result of scar contractures. ${ }^{6)} \mathrm{HA}$ is rarely observed in Caucasians, ${ }^{2)}$ unlike in Asians. However, to the best of our knowledge, few studies exist about the analysis and classification of alar rim 
deformities in Asian patients. Additionally, because of the lack of an assessment tool that could be used to address predictors for unsatisfactory outcomes preoperatively, an analysis of patients' concerns and expectations about their deformities might be useful to predict surgical success and patient satisfaction. ${ }^{7)}$ Therefore, we aimed to analyze alar rim deformities in Koreans undergoing primary rhinoplasty and evaluate their aesthetic concerns and expectations according to the type of deformity as a guide for surgeons in planning rhinoplasty.

\section{MATERIALS AND METHODS}

This study involved a retrospective review of patients' medical records and preoperative photographs after undergoing primary rhinoplasty at Kyung Hee University Hospital at Gangdong between January 2013 and December 2018. The exclusion criteria were as follows: 1) age less than 18 years, 2) revision rhinoplasty, 3) craniofacial anomalies, and 4) foreign descent. Before surgery, photo documentation including the frontal profile, lateral (right and left), oblique (right and left), and basal views were taken from all patients. Additionally, preoperative questionnaires regarding basic personality traits of patients, patients' complaints about their nose, reasons for receiving the operation, and postoperative expectations were documented (Supplementary Material). ${ }^{8)}$ This study was ap- proved by the Institutional Review Board of Kyung Hee University Hospital at Gangdong (IRB No. 2019-12-041) and the board granted a waiver for written informed consent because of the retrospective nature of the study.

For evaluating outcome measures, we analyzed patients' preoperative photographs and categorized patients' alar shapes into one of the following seven deformities with multiple choices: HC, RC, HA, RA, VA, CA, and TA (Fig. 1). Patients without any of the above deformities were classified as normal, whereas patients with two or more deformities were classified as those with multiple deformities. The categorization of alar shapes was determined by one of the authors (Tae Hyun Kim) of the present study. Additionally, esthetic concerns including complaints about their nose and patients' expectations were analyzed using questionnaires according to the type of deformity.

For statistical analyses, chi-squared analysis and Fisher's exact test were used to compare two nominal variables. All statistical analyses were performed using the Statistical Package for the Social Sciences (SPSS) version 25.0 (IBM Corp., Armonk, NY, USA). $p<0.05$ was considered statistically significant.

\section{RESULTS}

A total of 336 patients (71 females and 265 males) with a

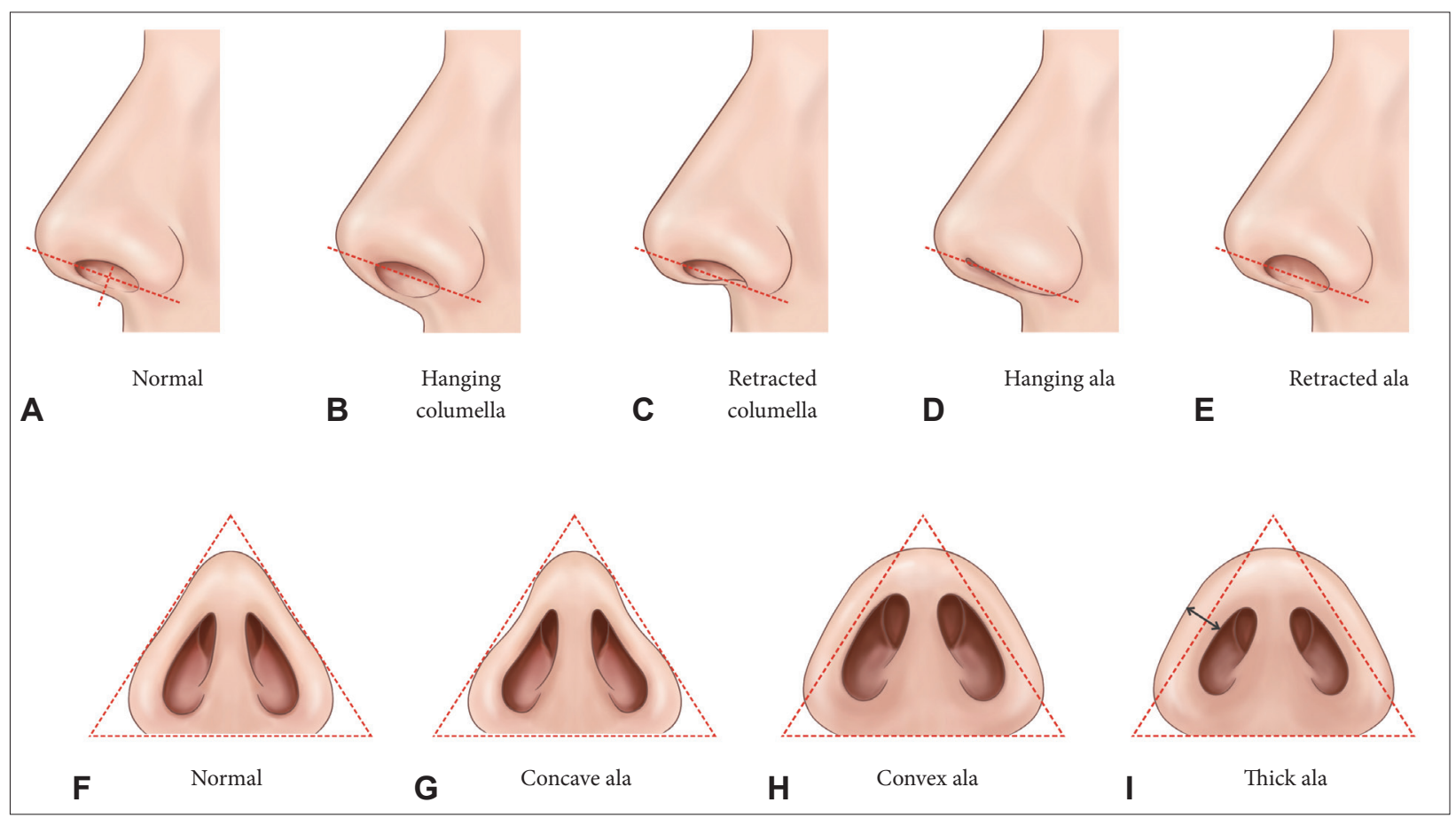

Fig. 1. Types of alar rim deformities. A-E: Alar-columellar relationship from the lateral view. A: Normal. B: Hanging columella (HC). C: Retracted columella (RC). D: Hanging ala (HA). E: Retracted ala (RA). F-I: Alar rim shape on the basal view. F: Normal. G: Concave ala (CA). H: Convex ala (VA). I: Thick ala (TA). Reproduced from Gunter JP et al. (1996) $)^{3)}$ and Guyuron B (2001) ${ }^{5}$ with permission from Wolters Kluwer Health. 
mean age of $27.9 \pm 11.3$ years (range, $18-75$ years) were included in this study. According to the age group, patients in their twenties ( $n=148,44.0 \%)$ were the most common, followed by patients in their teenage years $(n=82,24.4 \%)$, thirties $(n=57,17 \%)$, and forties $(n=29,8.6 \%)$. The mean body mass index (BMI) was $23.0 \pm 3.2 \mathrm{~kg} / \mathrm{m}^{2}$ (range, $16.2-36.9 \mathrm{~kg} / \mathrm{m}^{2}$ ). Of the enrolled patients, 38 (11.3\%) had no alar rim deformities, and the other 298 patients (88.7\%) had one or more of the alar rim deformities. The prevalence of alar rim deformities is represented in Table 1. Based on multiple choices, the most prevalent deformity type was HA (59.2\%), followed by VA (53.3\%) and TA (32.1\%). There was a sex-specific difference in the occurrence of RC and VA with a male predominance. Based on the frequencies of accompanying alar rim deformities, 107 (35.9\%) patients had single deformities, whereas 191 patients $(64.1 \%)$ had at least two or more alar rim

Table 1. Prevalence of alar rim deformities with multiple responses

\begin{tabular}{lcccc}
\hline \multicolumn{1}{c}{ Alar shape } & Male $(\mathrm{n}=265)$ & Female $(\mathrm{n}=71)$ & Total $(\mathrm{n}=336)$ & $\mathrm{p}$-value \\
\hline Normal & $27(10.2)$ & $11(15.5)$ & $38(11.3)$ & 0.210 \\
Hanging columella & $26(9.8)$ & $7(9.9)$ & $33(9.8)$ & 0.990 \\
Retracted columella & $36(13.6)$ & $2(2.8)$ & $38(11.3)$ & 0.011 \\
Hanging ala & $156(58.9)$ & $43(60.6)$ & $199(59.2)$ & 0.796 \\
Retracted ala & $30(11.3)$ & $3(11.3)$ & $38(11.3)$ & 0.990 \\
Concave ala & $4(1.5)$ & $27(38.0)$ & $179(53.3)$ & 0.155 \\
Convex ala & $152(57.4)$ & $19(26.8)$ & $108(32.1)$ & 0.004 \\
Thick ala & $89(33.6)$ & $33(46.5)$ & $191(56.8)$ & 0.276 \\
Two or more deformities & $158(59.6)$ & & & 0.100 \\
\hline
\end{tabular}

Values are presented as $\mathrm{n}(\%)$

Table 2. Aesthetic concerns according to the type of deformity

\begin{tabular}{|c|c|c|c|c|c|c|c|c|c|}
\hline Aesthetic concerns & Normal & $\begin{array}{l}\text { Hanging } \\
\text { columella }\end{array}$ & $\begin{array}{l}\text { Retracted } \\
\text { columella }\end{array}$ & $\begin{array}{c}\text { Hanging } \\
\text { ala }\end{array}$ & $\begin{array}{c}\text { Retracted } \\
\text { ala }\end{array}$ & $\begin{array}{c}\text { Concave } \\
\text { ala }\end{array}$ & $\begin{array}{c}\text { Convex } \\
\text { ala }\end{array}$ & $\begin{array}{l}\text { Thick } \\
\text { ala }\end{array}$ & $\begin{array}{l}\text { Two or more } \\
\text { deformities }\end{array}$ \\
\hline Low dorsum & $\mathrm{N}$ & $\mathrm{N}$ & $\mathrm{N}$ & $\mathrm{N}$ & $\mathrm{N}$ & $\mathrm{N}$ & $\mathrm{N}$ & $\mathrm{Y}^{\dagger}$ & $\mathrm{Y}^{\dagger}$ \\
\hline Crooked nose & $\mathrm{N}$ & $\mathrm{N}$ & $\mathrm{N}$ & $\mathrm{N}$ & $\mathrm{N}$ & $\mathrm{N}$ & $\mathrm{N}$ & $\mathrm{Y}^{\dagger}$ & $\mathrm{N}$ \\
\hline Hump nose & $\mathrm{N}$ & $\mathrm{Y}^{*}$ & $\mathrm{~N}$ & $\mathrm{~N}$ & $\mathrm{~N}$ & $\mathrm{~N}$ & $\mathrm{~N}$ & $\mathrm{Y}^{*}$ & $\mathrm{~N}$ \\
\hline Very wide alar base & $\mathrm{N}$ & $\mathrm{N}$ & $\mathrm{N}$ & $\mathrm{N}$ & $\mathrm{N}$ & $\mathrm{N}$ & $\mathrm{N}$ & $\mathrm{Y}^{\dagger}$ & $\mathrm{Y}^{\dagger}$ \\
\hline Poorly defined tip & $\mathrm{N}$ & $\mathrm{N}$ & $\mathrm{N}$ & $\mathrm{N}$ & $\mathrm{N}$ & $\mathrm{N}$ & $\mathrm{N}$ & $\mathrm{Y}^{\dagger}$ & $\mathrm{Y}^{\dagger}$ \\
\hline Under projected tip & $\mathrm{N}$ & $\mathrm{Y}^{\dagger}$ & $\mathrm{N}$ & $\mathrm{N}$ & $\mathrm{N}$ & $\mathrm{N}$ & $\mathrm{N}$ & $\mathrm{N}$ & $\mathrm{N}$ \\
\hline Large nostrils & $\mathrm{N}$ & $\mathrm{N}$ & $\mathrm{N}$ & $\mathrm{N}$ & $\mathrm{N}$ & $\mathrm{N}$ & $\mathrm{N}$ & $\mathrm{Y}^{*}$ & $\mathrm{Y}^{*}$ \\
\hline Very wide middle third & $\mathrm{N}$ & $\mathrm{N}$ & $\mathrm{N}$ & $\mathrm{N}$ & $\mathrm{N}$ & $\mathrm{N}$ & $\mathrm{Y}^{*}$ & $\mathrm{Y}^{\dagger}$ & $\mathrm{N}$ \\
\hline
\end{tabular}

$\mathrm{N}: \mathrm{p}>0.05 ; \mathrm{Y}^{*}: \mathrm{p}<0.05 ; \mathrm{Y}^{\dagger}: \mathrm{p}<0.01$

Table 3. Desired shape according to the type of deformity

\begin{tabular}{lccccccccc}
\hline \multicolumn{1}{c}{ Desired shape } & Normal & $\begin{array}{c}\text { Hanging } \\
\text { columella }\end{array}$ & $\begin{array}{c}\text { Retracted } \\
\text { columella }\end{array}$ & $\begin{array}{c}\text { Hanging } \\
\text { ala }\end{array}$ & $\begin{array}{c}\text { Retracted } \\
\text { ala }\end{array}$ & $\begin{array}{c}\text { Concave } \\
\text { ala }\end{array}$ & $\begin{array}{c}\text { Convex } \\
\text { ala }\end{array}$ & $\begin{array}{c}\text { Thick } \\
\text { ala }\end{array}$ & $\begin{array}{c}\text { Two or more } \\
\text { deformities }\end{array}$ \\
\hline Straighten the nose & $\mathrm{N}$ & $\mathrm{N}$ & $\mathrm{N}$ & $\mathrm{N}$ & $\mathrm{N}$ & $\mathrm{N}$ & $\mathrm{N}$ & $\mathrm{Y}^{*}$ & $\mathrm{~N}$ \\
Sharpen the tip & $\mathrm{N}$ & $\mathrm{N}$ & $\mathrm{N}$ & $\mathrm{Y}^{*}$ & $\mathrm{~N}$ & $\mathrm{~N}$ & $\mathrm{~N}$ & $\mathrm{Y}^{*}$ & $\mathrm{Y}^{*}$ \\
Rotate the tip & $\mathrm{N}$ & $\mathrm{Y}^{*}$ & $\mathrm{~N}$ & $\mathrm{~N}$ & $\mathrm{~N}$ & $\mathrm{~N}$ & $\mathrm{~N}$ & $\mathrm{~N}$ & $\mathrm{~N}$ \\
Narrow the alar base & $\mathrm{N}$ & $\mathrm{N}$ & $\mathrm{N}$ & $\mathrm{Y}^{*}$ & $\mathrm{~N}$ & $\mathrm{~N}$ & $\mathrm{~N}$ & $\mathrm{Y}^{\dagger}$ & $\mathrm{Y}^{*}$ \\
\hline
\end{tabular}

$\mathrm{N}: \mathrm{p}>0.05 ; \mathrm{Y}^{*}: \mathrm{p}<0.05 ; \mathrm{Y}^{\dagger}: \mathrm{p}<0.01$ 
Similarly, patients with TA had various demands for correction regarding their nose, such as straightening of the nose ( $\mathrm{p}=0.026)$, sharpening of the tip $(\mathrm{p}=0.012)$, and narrowing of the alar base ( $\mathrm{p}=0.001)$ (Table 3$)$. Patients with HA and multiple deformities wanted a sharper tip $(\mathrm{p}<0.05)$ and narrower alar base $(\mathrm{p}<0.05)$. Patients with HC wanted to rotate their tip $(\mathrm{p}=0.039)$.

\section{DISCUSSION}

In this study, we found that the most common alar rim deformities in Koreans who underwent primary rhinoplasty were HA, followed by VA and TA, contrary to a previous study reporting RA as the most common type of deformity in Caucasians. ${ }^{2)}$ RA was not frequently observed in our cohort. To the best of our knowledge, this is the first large-scale study analyzing the characteristics of alar rim deformities in Asian patients undergoing primary rhinoplasty. We also analyzed patients' esthetic concerns and expectations based on the type of deformity for better understanding patient characteristics.

Although alar deformity is commonly encountered, its correction through rhinoplasty is challenging because of the possibility of unexpected results with a risk of scar formation and possible nostril asymmetry. ${ }^{4)}$ Correction of HA, which was the most prevalent type of alar deformity in our study, is relatively simple and can be easily performed by removing an elliptical alar lining along with a proportional amount of subcutaneous tissue while leaving the skin intact. ${ }^{4)}$ In contrast, correction of alar retraction, which is the most prevalent deformity type in Caucasians, may be one of the most challenging procedures because of the lack of adequate soft tissue in rhinoplasty. ${ }^{69)}$ Scar contracture due to a previous surgery is a common cause of alar retraction in Asians. Correction of TA, the third most common type in our study, can also be challenging. Although variations among individuals exist, Asian noses are characterized by thick skin with poor tip definition. ${ }^{10)}$ Additionally, delicate and weak alar cartilages along with thin, weak septal cartilages in Asians cause difficulties in shaping tip. ${ }^{10)}$

On the other hand, multiple deformities with two or more alar deformities were the second most common deformity type, suggesting that the current classification system is not suitable for Asian patients. According to a previous study, ${ }^{11)}$ Asians had noses with shorter heights and wider alar bases than Caucasians did. ${ }^{1112)}$ Additionally, alar flaring and thick side walls were common characteristics of Asian noses. In this regard, a researcher classified alar bases into six types depending on the surgical technique used in Asians during rhinoplasty. ${ }^{4)}$ However, to the best of our knowledge, no universally accepted classification system takes into account the charac- teristics of Asian ala. Our findings show the necessity for a new systemic alar classification for Asian rhinoplasty, which is not only limited to the basal view but also considers the alarcolumellar relationship, which will be helpful for a detailed analysis and surgical success.

Our results showed that patients with TA were dissatisfied with the shape of their noses and had many requests. Both surgeons and patients must identify patients who would have a high probability of dissatisfaction with the surgical outcome before surgery. Previously known risk factors for poor postoperative satisfaction include young age, male sex, frequent cosmetic surgery, and unrealistic expectations. ${ }^{13)}$ However, no objective methods exist to screen these problematic patients before surgery. ${ }^{7)}$ A study using computer simulation found that patient's satisfaction did not differ whether preoperative computer simulation was used or not, although it provided a preoperative assessment of the preferred external nasal appearance. ${ }^{14)}$ A recent meta-analysis reported that the Rhinoplasty Outcome Evaluation comprising six questions regarding nasal shape, patient's perception on the nasal appearance, and breathing ability was useful to evaluate postoperative satisfaction by quantifying the benefits following esthetic rhinoplasty. ${ }^{15)}$

One of the strengths of our findings is that we classified alar rim deformities in Asians and found different esthetic concerns and expectations based on their morphological types. Patients with TA had various reasons for dissatisfaction about their nose and several demands for correction. It is important because TA was the third most common deformity type in our study and also commonly reported in Asians. In addition, management of the associated thick skin is challenging and has limitations in achieving the desired shape. ${ }^{10)}$ Moreover, the alar rim area is prone to delayed changes because of scarring of the soft triangle and insufficient structural support, ${ }^{1)}$ resulting in outcomes that are different from preoperative expectations. Rhinoplasty is known to be the most repetitively requested procedure, followed by chin and breast surgery. ${ }^{16)}$ Hence, sufficient consultation and strict patient selection should not be overlooked from the consultation phase.

Our study has several limitations. First, alar rim deformities were assessed by only one rhinologist; thus, validity and interrater reliability could not be assessed. However, the aim of this study was not to perform the reliability analysis, but to focus on the classification of alar rim deformity in Korean. In the same vein, nasal deformities other than ala that could also affect aesthetic concerns were not dealt with in this study. Second, standardized validated questionnaires were not used. We have conventionally used our own questionnaire in our institution and are planning to adopt validated one. Third, surgical techniques and postoperative outcome were not assessed in this study. The treatment outcome might be different ac- 
cording to preoperative morphological type, psychological, and functional factors. Based on the findings in this study, we are expecting next study to assess the effect of preoperative alar rim deformities on the postoperative outcomes and satisfaction.

In conclusion, we classified alar rim deformities in Korean rhinoplasty patients and analyzed their unique esthetic concerns based on their morphological type. Contrary to Caucasians, the most prevalent deformity type in Koreans was HA, followed by VA and TA. Patients with TA had several reasons for being dissatisfied with their nose and various demands for correction. Our results justify the necessity for a new alar rim classification system specialized in Asians. A detailed assessment of deformities and patient-oriented consultations will lead to satisfactory outcomes in patients undergoing rhinoplasty.

\section{Supplementary Materials}

The online-only Data Supplement is available with this article at https://doi.org/10.18787/jr.2021.00365.

\section{Conflicts of Interest}

The authors have no potential conflicts of interest to disclose.

\section{Author Contributions}

Conceptualization: Kun Hee Lee. Data curation: Tae Hyun Kim. Formal analysis: Ho Yun Lee. Funding acquisition: Su Jin Kim. Methodology: Tae Hyun Kim. Project administration: Kun Hee Lee. Resources: Kun Hee Lee. Supervision: Kun Hee Lee. Validation: Tae Hoon Kim. Visualization: Su Jin Kim. Writing_original draft: Su Jin Kim. Writing—review \& editing: all authors.

\section{ORCID iDs \\ Su Jin Kim \\ Ho Yun Lee \\ Tae Hyun Kim \\ Tae Hoon Kim \\ Kun Hee Lee}

\section{Funding Statement}

This work was supported by a grant of National Medical Center, Republic of Korea (grant number: NMC2021-General Research Program-02).

\section{REFERENCES}

1) Unger JG, Roostaeian J, Small KH, Pezeshk RA, Lee MR, Harris R, et al. Alar contour grafts in rhinoplasty: a safe and reproducible way to refine alar contour aesthetics. Plast Reconstr Surg 2016;137(1):52-61.

2) Totonchi A, Guyuron B. Alar rim deformities. Clin Plast Surg 2016; 43(1):127-34.

3) Gunter JP, Rohrich RJ, Friedman RM. Classification and correction of alar-columellar discrepancies in rhinoplasty. Plast Reconstr Surg 1996;97(3):503-9.

4) Choi JY. Alar base reduction and alar-columellar relationship. Facial Plast Surg Clin North Am 2018;26(3):367-75.

5) Guyuron B. Alar rim deformities. Plast Reconstr Surg 2001;107(3):85663.

6) Kim JH, Park SW, Oh WS, Lee JH. New classification for correction of alar retraction using the alar spreader graft. Aesthetic Plast Surg 2012;36(4):832-41.

7) Herruer JM, Prins JB, van Heerbeek N, Verhage-Damen GWJA, Ingels KJAO. Negative predictors for satisfaction in patients seeking facial cosmetic surgery: a systematic review. Plast Reconstr Surg 2015; 135(6):1596-605.

8) Hah YM, Jung SY, Kang JW, Huh JH, Min JY, Kim SW, et al. Psychological characteristics and aesthetic concerns of male patients seeking primary rhinoplasty. Korean J Otorhinolaryngol-Head Neck Surg 2018; 61(5):252-7.

9) Jung DH, Kwak ES, Kim HS. Correction of severe alar retraction with use of a cutaneous alar rotation flap. Plast Reconstr Surg 2009;123(3): 1088-95.

10) Jin HR, Won TB. Rhinoplasty in the Asian patient. Clin Plast Surg 2016; 43(1):265-79.

11) Farkas LG, Hreczko TA, Deutsch CK. Objective assessment of standard nostril types--a morphometric study. Ann Plast Surg 1983;11(5): 381-9.

12) Hwang TS, Kang HS. Morphometry of nasal bases and nostrils in Koreans. Ann Anat 2003;185(2):189-93.

13) Tanna N, Nguyen KT, Ghavami A, Calvert JW, Guyuron B, Rohrich RJ, et al. Evidence-based medicine: current practices in rhinoplasty. Plast Reconstr Surg 2018;141(1):137e-5le.

14) Yu MS, Jang YJ. Preoperative computer simulation for Asian rhinoplasty patients: analysis of accuracy and patient preference. Aesthet Surg J 2014;34(8):1162-71.

15) Yang F, Liu Y, Xiao H, Li Y, Cun H, Zhao Y. Evaluation of preoperative and postoperative patient satisfaction and quality of life in patients undergoing rhinoplasty: a systematic review and meta-analysis. Plast Reconstr Surg 2018;141(3):603-11.

16) Wilson JB, Arpey CJ. Body dysmorphic disorder: suggestions for detection and treatment in a surgical dermatology practice. Dermatol Surg 2004;30(11):1391-9. 